\title{
The Pragmatic Analysis of Wilde's Comedy: The Importance of Being Ernest
}

\author{
Janin Jafari \\ School of Languages, Cultures, and Linguistics, Monash University, Melbourne, Australia
}

\begin{abstract}
This paper attempts to pragmatically analyze the verbal behavior of the protagonists of Oscar Wilde's play 'The importance of being Ernest'. The goal of the research is to investigate the conversations in this literary genre, comedy of manners, from a pragmatic perspective. The analysis covers various pragmatic concepts such as implicature and conversational maxims. The focus of interest is the dyads which create triggers for particular implications in this literary genre. This paper applies Grice's Cooperative Principle to this literary genre to explore which conversational maxims are observed, flouted or violated, and to identify whether the speakers violate the maxims deliberately, unostentatiously or unconsciously. It then illustrates the implicature behind the violated maxim. The results of this study show that in most cases speakers tend to violate the Grice's four maxims of Quality, Manner, Quantity, and Relation respectively, in order to create the intended implicatures.
\end{abstract}

Index Terms-Grice's maxims, implicature, cooperative principle, pragmatics

\section{INTRODUCTION}

Since the inception of the discipline of linguistics, linguists have begun to provide a comprehensive theory of language as a specialized tool for the communication of thoughts, feeling, and purposes. To this end, a number of theories have been written according to the linguists' foci and interests. One of these approaches is 'pragmatics' whose main aim of communication is the exchange of information. Pragmatics comes forth as an independent field of study mainly due to the frequent failures of semantics in providing sufficient explanations with respect to meaning. While semantics concentrates on the literal meaning of an expression, it does not consider the context in which it is expressed (Cutting, 2002). Pragmatics, on the contrary, realizes the importance of context, especially in showing the meaning underlying a certain expression. Thomas (1995) explains that meaning in semantics is the dictionary meanings of words or phrases, while meaning in pragmatics is the speaker's intention. Thus, meaning in pragmatics is different from meaning in semantics in connection with a speech situation.

According to Thomas (1995), the interlocutors take physical, social, and linguistic contexts as well as the potential meaning of the utterances into account to make the appropriate meaning in an exchange. In fact, pragmatics caters for not only the exact and literal meaning of words and sentences, but also the various aspects of meaning that come from the intention of the speaker, linguistic performance, and the background knowledge of the speaker and listener. Thomas (1995) defines pragmatics as "meaning in interaction, since this takes into account of the different contribution of both speaker and hearer as well as that of utterance and context to the making of meaning' (p. 23). Yule (1985) explains pragmatics as a branch of language that focuses on how participants interpret what they mean. Meaning in pragmatics has a central role in communication which occurs in social organization; therefore, pragmatics takes into consideration both the study of meaning and parts of linguistics which connect language with social, psychological and philosophical aspects of linguistics.

Aitchison (1995) emphasizes that in a narrow sense pragmatics investigates how listeners get the intended meaning of the speakers, whereas in a broader sense it concerns with certain principles followed by interlocutors when communicating with each other. Yule (1996) believes that people are members of various social groups and follow principles or certain patterns of behavior which are expected within the group. Grice (1989) argues that people basically try to cooperate to convey their intentions and construct meaningful conversations. Grice (1975) proposes that conversation is based on a shared principle of cooperation, and his work on the Cooperative Principle (CP) led to the development of pragmatics as a distinct discipline within linguistics. Since the major aim of communication in pragmatics is to give and receive information, people try to adopt a cooperative behavior to convey their intentions and transfer their utterances implicitly. In this regard, Grice (1975) points out that communication acts depend on the Cooperative Principle and interlocutors try to be cooperative with each other in most of the conversational exchanges, and proposes some principles in order to account for the cooperative behavior of participants in their conversations.

Grice (1975) explained both cooperative principle and conversational implicature in his article "Logic and Conversation" and claimed that the process of producing and perceiving of these implicatures is based on the following principles: "Make your conversational contribution such as is required, at the stage at which is occurs, by the accepted purpose or direction of the talk exchange in which you are engaged" (p. 48). It is clear that the concept of rationality plays an important role in his discussion of cooperation and the Cooperative Principle tries to make explicit rational 
principles which are observed by people through conversation. Grice's theory rests on the assumption that there is a distinction between saying and meaning, therefore, speakers can produce the implicit meaning and their listeners are able to perceive that intended meaning from their conversations. He argues that participants follow certain rules and patterns in their conversations; consequently, they are expected to make their utterances informative and relevant.

\section{A. Grice's Maxims}

Grice (1975) developed four conversational maxims, which are subsumed under a general principle he called the Cooperative Principle:

\section{Quantity}

Speaker's contribution is as informative as required.

\section{Quality}

Speaker tells the truth or provides adequate evidence for his/her statement.

\section{Relation}

Speaker's response is relevant to the topic of the conversation.

\section{Manner}

Speaker speaks straightforwardly and clearly and avoids ambiguity or obscurity.

These maxims identify a particular set of patterns in interaction and speakers are expected to make their utterances informative, truthful, clear and relevant. Grice (1989) believes that these conversational maxims help participants to produce inferences beyond the surface meaning of an utterance. Bowe and Martin (2006) state that if interlocutors are engaged in a cooperative conversation, these maxims will show the norms that listener can expect speakers to have followed. Grice (1989) divides inferences into two categories: first, inferences that are straightforward and listener can get the speaker's intention directly, second, inferences that are conveyed by violating those maxims, which are called 'implicature' by Grice (1975).

According to Davies (2008), when the semantic content of utterances does not follow the Gricean maxims, while the speaker is engaged in CP, the audience should go beyond the surface to understand the implied meaning of the utterance. Grice (1989) describes that speakers sometimes fail to observe a maxim, and makes a distinction among three types of implicatures in which a maxim is flouted, violated or clashed. In the first case, the interlocutor breaks the maxims deliberately to create meaning. In the second case, the speaker may be misled due to hidden non-cooperation, and in the last case, the interlocutor cannot accomplish a maxim in order to observe the social convention of politeness.

According to Thomas (1995), utterances may conform to the maxims or may disobey them by infringing, opting out, and flouting or violating. The infringement of the maxims is because of the speaker's imperfect knowledge of linguistic. When speakers decided to be uncooperative, they opt out of observing the maxims. The flouting of the maxims occurs "when speakers appear not to follow the maxims but expect hearers to appreciate the meaning implied..." (Cutting, 2003, p. 37), therefore, the speakers break the maxims intentionally while trying to be cooperative in the conversation. In this case, the speakers deliberately violate the maxims which would result in misinterpretation. Levinson (1983) declares that it is the hearer who needs to determine what the speakers utter as conforming to or violating the maxims to a certain degree.

\section{OBJECTIVE OF THE STUDY}

The present study tries to analyse the conversations in a literary genre called 'comedy of manners', especially the work of Oscar Wilde (1895) 'The Importance of Being Ernest', to investigate which maxims are the most frequent violated maxims and how are these maxims are violated which has not been studied in this literary genre yet. Therefore, this study selects the dyads which create triggers for particular implications in this literary genre, next, applies cooperative principle to this literary genre to see which maxims are violated, then, identifies whether the speaker violates the maxims deliberately, unostentatiously or unconsciously, and finally illustrates the implicature behind violating the maxims.

\section{SignifiCANCE OF THE STUDY}

As mentioned before recognizing the conversational implicature has a central role in understanding a text or discourse. Thus, the main concern of this study is to identify the role of the conversational implicature in comprehension of a written text or a spoken one. Related to pedagogical aspects of pragmatic competence Devine (1982) holds that for learning a second language well learner should acquire discourse structure and communicative competence as well as grammatical forms. A reader or listener who does not possess enough knowledge about the conversational implicature will not be able to get the intended message or may even understand it wrongly. Richards (2006) concludes that second language learners need to acquire not only grammatical forms, but also conversational competence which is one of the important dimensions of the second language learning. He also believes that depending on the degree of universality of the Gricean maxims, they would be relevant to conversation in a second language.

Therefore, the significance of this study is of the following perspectives: first, it is an attempt to examine how it is possible to convey an intended meaning through conversational maxims; second, the findings of this study may have some pedagogical benefits for both the teachers to use the pragmalinguistic aspects of the language in their teaching 
programs, and learners of EFL and ESL courses to understand the utterances correctly. Third, it is hoped that this study will help translators, since an awareness of the conversational implicature will give them new possibilities and enable them to translate the meaning of the speaker to their appropriate equivalents.

\section{LITERATURE REVIEW}

Since the notion of Cooperative Principle and the conversational maxims introduced by Grice in 1975, a number of studies have been done in order to examine its universality, applicability and predictability in relation to different types of spoken and written language within different situation and cultures. Some of those are: Devine (1982), Bouton (1988), Sarami, (1993), Alvaro (2011), and Kheirabadi and Aghagolzadeh (2012).

Devine (1982) managed two pilot studies; in the first study he assessed the universality of the conversational maxims noted by Grice in 1976 and also examined the process of creating implicatures. By comparing the degree of comprehension of the given implicature instances in English, he tested the ability of the understanding of implicature in L2, among native and non-native speakers of English. Devine (1982) chose 15 L2 language students and 15 American students as his subjects. The L2 students were in advanced English classes at Michigan State University. Their levels were determined by placement test. This group consisted of ten males and five females with various language backgrounds such as, Farsi, Japanese, Spanish, and Korean, and their ages ranged from 18 to 43. The other group, namely American students, studied in an introductory level course on language at Michigan State University. This group consisted of eight females and seven males who ranged in age from 19 to 28 . They were given brief descriptions of 15 situations to read, and all contained an example of conversational implicature. Researcher devoted three scores to the responses: a) the subjects got the message, b) the subjects didn't get the message, c) it was not possible to determine. The conversational implicatures were based on the three suggested types by Grice (1976) as: flouting and clashing of maxims, and also unstated connection between statements. The results showed that the two groups understood the same, with a little difference; however, in the case of flouting the maxim of Quantity the data were more problematic. Although in different cultures there are different interpretations.

Bouton, L.F. (1988) drew attention to the crucial role of cultural background by performing the following pilot study. He considered two basic assumptions in his study: first, American native speakers of English were asked to interpret some utterances, and if they drew the same implicatures and interpreted in the same way, then it could be a native speaker (NS) norm. Then nonnative speakers' (NNS) responses compared with NS norms in a multiple-choice test in order to identify the extent to which NSs and NNSs interpret the same implicatures in the same way. The second assumption was that, researchers provided a brief description of a situation with enough contextual information within a short dialogue, then a native speaker allowed to interpret any implicature recognized in the dialogue.

To test these two assumptions, the researcher provided a number of open-ended questions and distributed to 60 American NSs and 79 NNSs. They were asked to read a description of a situation within a dialogue in which each character conveyed a message by using implicatures and following each dialogue there was a question leading the subjects to guess the message within the utterance. Then subjects were asked to state the intended meaning of the speaker by their own words. Their responses to the open-ended questions supported two mentioned assumptions, and the most influential NS interpretation made the counterpart multiple-choice questions and distributed them to 436 NNSs entering the University of Illinois. A second group of 28 American NSs served as the controlled group. Time limit was not considered in the test, the cultural background of the subjects was an independent variable, and the individual's score on the implicature test was the dependent variable. Seven different groups of the study were: Germans, Spanish/Portuguese, Taiwanese/Chinese, Koreans, Japanese, Mainland Chinese and Americans. He observed that implicature tests even for NSs did not have the same difficulty and some types of implicatures were easier than such as the maxim of Relevance, but the maxim of Quantity were more difficult than the others, he also considered the influence of cultural background on the performance on both difficult and easy items. The results of the data analysis revealed that NSs interpreted the implicatures of the dialogue in a different way from NNSs. Related to the degree of influence of the cultural background on the performance of subjects in drawing implicatures, Bouton (1988) concluded that employing implicature in cross-cultural communication is a potential obstruction to the success of their interaction.

Sarami (1993) carried out another study which again showed the role of implicature within a text. He picked up 105 Persian dyads from four current satiric periodicals such as Golagha, Khorjin, Tanz va Karikator and Juvalduz. He analyzed Persian satires in terms of observing or violating Gricean maxims in order to find out the conversational implicatures. The obtained results revealed that in most cases, Persian satires tend to observe Gricean maxims, but the other cases showed a tendency to violate Grice's four maxims in order to produce implicatures which are orderly: first, the maxim of Quality; second, the maxim of Manner; third, the maxim of Quantity, and forth; the maxim of Relation. Sarami (1993) concluded that there is a high frequency of violating the maxim of Quality in Persain satires which demand the reader or receiver much less thinking. Therefore, the reader can get intended meaning of the satire by exploiting his/her background knowledge and knowing the meaning of the words. In contrast, when the maxims of Quantity, manner and relation are violated, the reader cannot understand the conversational implicature by relying only on the present wording of the text.

Alvaro (2011) conducted a pragmatic analysis of the use of presupposition and implicatures as fundamental resources in Woody Allen's film Anything Else. The author investigated 59 scenes of this film and analyzed the characters' 
interactions quantitatively. The results show that presupposition and implicature, especially those that generated by the non-observance of the Gricean maxims and their flouting, play an important role in the creation of humor in this film.

Kheirabadi and Aghagolzadeh (2012) reviewed a wide range of Galtung and Rouge's news values (newsworthiness of an event) lists suggested by media scholars and linguists from 50 years ago and propose Grice's cooperative maxims as linguistic set of news values. The authors indicated that an indispensible number of news values, which are defined clearly by media researchers in recent decades, are rewording of these maxims. In fact, journalists are aware of these pragmatic maxims while writing their news events.

\section{Methodology}

\section{Subjects}

The subjects of this study are characters in English comedy in which men and women living under specific social codes, especially the codes of the middle and upper classes which are marked by elegance, wit, and sophistication.

\section{Materials of the study}

The data for the present study is based on the implicatures taken from 'The importance of being Ernest', written by Wilde, O. (1895).

\section{Data analysis}

By adopting pragmatics and conversation analysis, the selected comedy will be analyzed as follows:

First, those dyads in which there are triggers of maxim violating will be picked up. Second, those dyads will be studied carefully to determine which maxims are flouted. Third, the implicatures behind the violation will be defined. The fourth stage would be to categorize those dyads under the four Gricean maxims.

\section{ANALysis OF THE Data}

The data for the existing study include those conversations in which there are traces of violating a number of Gricean maxims. The analysis of the data is based on the conversational maxims and implicatures. The selected samples are as follows:

(1) Algernon: Did you hear what I was playing, Lane?

Lane: I did not think it is polite to listen, sir.

Lane ostentatiously violating the maxim of Quality, he could simply have replied: 'No' - this would give the maximum amount of information possible in the situation. Instead, Lane gives a more informative response. Thus, he conveys the existent difference between middle and upper classes. (p. 5)

(2) Algernon: How are you, my dear Ernest? What brings you up to town?

Jack: Oh, pleasure, pleasure! What else should bring one anywhere? Eating as usual, I see, Algy!

In this conversation the maxim of Quality is violated. Jack travels to town because he has fallen in love with Gwendolen. In fact, he has come up to town expressly to propose to her, but he says pleasure which is untrue. (p. 6)

(3) Algernon: How immensely you must amuse them! [Goes over and takes sandwich.] By the way, Shropshire is your county, is it not?

Jack: Eh? Shropshire? Yes, of course. Why all these cups? Why cucumber sandwiches? Who is coming to tea?

In this dialogue Jack violates the maxim of Quality, and he says something which is untrue about his address and then deliberately flouts the maxim of Relevance at the same time, because he wants to change the topic of their conversation and also wants to know who the guests are. (p. 7)

(4) Algernon: Yes, but that does not account for the fact that your small Aunt Cecily, who lives at Tunbridge Wells, calls you her dear uncle. Come, old boy, you hand much better have the thing out at once.

Jack: My dear Algy, you talk exactly as if you were a dentist. It is very vulgar to talk like a dentist when one is not a dentist. It produces a false impression.

Jack ostentatiously violates the maxim of Manner by using the word dentist, he intends to produce obscurity, but he means that Algy as a dentist pulls out words of his mouth. That is, he does not like to respond, but he has to. (p. 9)

(5) Algernon: You have invented a very useful young brother called Ernest, in order that you may be able to come up to town as of as you like. I have invented an invaluable permanent invalid called Bunberry, in order that I may be able to go down into the country whenever I choose. Bunbery is perfectly invaluable. If it was not for Bunbery's extraordinary bad health, for instance, I would not be able to dine with you at Willis's tonight, for I have been really engaged to Aunt Augusta for more than a week.

Jack: I have not asked you to dine with me anywhere tonight.

In this conversation Algy violates both maxims of Quantity and Quality. Algy fails to give the right amount of information and prompts his interlocutor to look for an implicature, and also makes a sentence which is untrue. He gives more information about their false brother and friend, and says he is invited by Jack which is completely untrue. In fact, he does not want to go to the Augsta's party. (p. 10)

(6) Lady Bracknell: It is very strange. This Mr. Bunbery seems to suffer from curiously bad health.

Algernon: Yes, poor Bunbery is a dreadful invalid. 
In this dialogue the maxim of Manner is violated, because the second subdivision of this maxim says, avoid ambiguity. Algy use the phrase 'dreadful invalid' which has 2 meanings: first, it means null; second, it means weak or disabled through illness or injury. Of course, this case of violating is deliberately. (p. 12)

(7) Lady Bracknell: It really makes no matter, Algernon. I had some crumpets with Lady Harbury, who seems to me to be living entirely for pleasure now.

Algernon: I hear her hair has turned quite gold from grief.

In this instance an implicature is generated by the (speaker) Algernon's saying something which is clearly false. Through the violation of the maxim of Quality, Algy wants to imply that Lady Harbury feels freedom after the death of her husband. (p. 12)

(8) Cecily: Oh, yes, Dr. Chasuble is a most learned man. He has never written a single book, so you can imagine how much he knows.

Cecily ostentatiously violates the maxim of Quality, because she believes that Dr. Chasuble does not have enough information, when he has never written a single book. (p. 9)

\section{IMPLICATION TO RESEARCH AND PRACTICE}

This research will have pedagogical implications for students and teachers of pragmatics. In order to communicate effectively, language learners need to acquire more than just the syntax and semantics of the language; they actually need to learn more about pragmatics. In this regard, Gricean conversational maxims would enable language learners to comprehend the intended meaning of other speakers and also convey their own messages successfully. One way of teaching and learning these maxims is through texts in different literary genres especially Comedy of manners.

\section{CONCLUSION AND RECOMMENDATIONS FOR FURTHER RESEARCH}

The existing study analyzed dyads in 'The importance of being Ernest', written by Oscar Wilde (1895), in terms of observing or violating Gricean maxims. The obtained results showed that in most cases interlocutors tend to violate Grice's four maxims in order to create implicatures. The violation of Grice's maxims is respectively: first, the maxim of Quality; second, the maxim of Manner; third, the maxim of Quantity; fourth and the last one is the maxim of Relation.

It is recommended that further research needs to be conducted due to the limited number of studies in this field related to other literary genres, languages and cultures. This study focused on written text; however, future researchers can collect data from naturally occurring conversation in different settings. They can also take other influential variables such as age, gender, and nationality into consideration.

\section{REFERENCES}

[1] Aitchison, J. (1995). Linguistics. London: Haodder and Stoughton.

[2] Alvaro, R. N. (2011). The role of conversational maxims, implicature and presupposition in the creation of humor: an analysis of Woody Allen's Anything Else (Master thesis). Retrieved from eprints.ucm.es/13386/1/MA _ Dissertation _ Ramiro _ Nieto _ (2011). pdf (accessed 20/8/2013).

[3] Bouton, L.F. (1988). A cross-cultural study of ability to implicatures in English. World Englishes, 7, 183-96.

[4] Cutting, J. (2002). Pragmatics and Discourse. London:Routledge.

[5] Davis, B. L. (2008). Grice's cooperative principle: meaning and rationality. Journal of Pragmatics, 39, $2308-2331$.

[6] Devine, J. (1982). A question of universality conversational principles and implicatures. In M. A. Clarke \& J. Handscomde (Eds.), TESOL (pp. 191-206). Washington DC: TESOL.

[7] Grice, H. P. (1975). Logic and conversation. In P. Cole \& J. L. Morgan (Eds.), Syntax and Semantics, (pp.41-58). New York: Academic Press.

[8] Grice, H. P. (1989). Studies in the way of words. Cambridge, MA: Harvard University Press.

[9] Kheirabadi, R. \& Aghagolzade, F. (2012). Gric's cooperative maxims as linguistic criteria for news selectivity. Theory and Practice in Language Studies, 2 (3), 547-53. http://dx.doi.org/10.4304/tpls.2.3.547-553.

[10] Levinson, S.C. (1983). Pragmatics. Cambridge: Cambridge University Press.

[11] Richards, J. C. (2006). Communicative language teaching today. Cambridge: Cambridge University Press.

[12] Sarami, V. (1993). A linguistic study of Persian contemporary socio-political satire. M.A. Thesis. Shiraz University, Shiraz, Iran.

[13] Thomas, J. (1995). Meaning in interaction: an introduction to pragmatics. London: Longman.

[14] Wilde, O. (1895). The importance of being Ernest. Retrieved from http://www.histage.com/playdetails.asp?PID=2228 (accessed 2/7/2013).

[15] Yule, G. (1985). The study of language. Cambridge: Cambridge University Press.

Janin Jafari was born in Tehran, Islamic Republic of Iran. She is a PhD candidate in Applied Linguistics at Monash University in Melbourne, Australia. She completed a Master's degree in TESOL at IAU in Shiraz, Iran, in 2000 and holds a BA in English translation from Persian to English and vice-versa.

She has been teaching English as a full-time lecturer for 10 years in different branches of Islamic Azad University in Tehran, Iran. She also has published: Jafari, J. (2013). Elicitation Questions in English and Persian Written Texts: A Comparative Study. World 
Journal of English Language, 3(2), 34-44. doi:10.5430/wjel.v3n2p34. Her main research interests are English as a Lingua Franca, Pragmatics, Conversation Analysis, and Communication Strategies.

Ms. Jafari is currently doing a PhD in English as a Lingua Franca at Monash University, Melbourne, Australia. 